\title{
Occupational Therapy
}

National Cancer Institute

\section{Source}

National Cancer Institute. Occupational Therapy. NCI Thesaurus. Code C121351.

Interventions and exercises intended to develop, recover, or maintain the ability of an

individual to accomplish their activities of daily living. 